Jurnal Homepage: http:/journal2.um.ac.id/index.php/jaa (p-ISSN: 2087-9695; e-ISSN: 2580-1015)

\title{
Pengaruh non-financial distress, koneksi politik, dan intensitas persediaan terhadap tax avoidance
}

\author{
Dudi Pratomo ${ }^{1}$, Kurnia ${ }^{1}$, Annisa Justica Maulani ${ }^{1}$ \\ ${ }^{1}$ Telkom University, Jl. Telekomunikasi Jl. Terusan Buah Batu, Bandung, Indonesia
}

\author{
Diterima: \\ 30 Juni 2020 \\ Direvisi: \\ 8 Oktober 2020, \\ 14 Oktober 2020 \\ Disetujui: \\ 20 Oktober 2020 \\ Korespondensi:
Dudi Pratomo
dudipratomo@
telkomuniversity.ac.id
DOI:
http://dx.doi.org/10.17977/
um004v8i22021p107
}

\section{PENDAHULUAN}

Menurut UU No. 16 Tahun 2009, pajak merupakan kewajiban orang pribadi atau badan untuk memberikan kontribusi kepada negara dengan imbalan tidak langsung. Pajak merupakan sumber utama pendapatan negara untuk menjalankan program pembangunan demi kesejahteraan masyarakat. Akan tetapi, wajib pajak merasa kewajiban membayar pajak adalah suatu beban karena dapat mengurangi daya beli perusahaan (Santoso \& Rahayu, 2013). Oleh karena itu, perusahaan berupaya untuk menghindari pembayaran pajak. Praktik ini berdampak pada tidak tercapainya rencana target penerimaan pajak dan realisasi penerimaan pajak makin lama makin menurun.

Target penerimaan pajak yang tidak tercapai disebabkan oleh beberapa faktor yang salah satunya adalah penerapan self assessment system. Sistem ini memberikan keleluasaan bagi wajib pajak untuk mengukur dan menilai kewajiban perpajakan secara mandiri sehingga wajib pajak menentukan sendiri besarnya pajak terutang (Mardiasmo, 2019). Akan tetapi, sistem ini membuka peluang bagi wajib pajak untuk menghindari pembayaran pajak. Pengurangan pembayaran pajak di bawah tarif pajak adalah praktik pengurangan pajak terutang dengan memanfaatkan kelemahan dalam peraturan perpajakan (Pohan, 2016). Selain itu, penghindaran pajak yang dilakukan perusahaan tidak terjadi secara kebetulan, tetapi telah diatur dalam strategi yang telah ditetapkan (Hanafi \& Harto, 2014).

Beberapa hal yang bisa mendorong perusahaan mempraktikan tax avoidance adalah kesulitan keuangan (financial distress), adanya koneksi politik (Ferdiawan \& Firmansyah, 2017), dan jenis perusahaan dengan kondisi intensitas persediaan yang tinggi (Adisamartha \& Noviari, 2015). Namun, masih terdapat inkonsistensi dari hasil-hasil penelitian tersebut sehingga topik penelitian ini masih relevan untuk dikaji kembali.

Kondisi pertama yang mendorong adanya tax avoidance adalah non-financial distress yang merupakan suatu kondisi keuangan perusahaan yang stabil atau sehat. Praktik tax avoidance adalah suatu hal yang wajar karena dilakukan secara legal (Dyreng, Hanlon, \& Maydew, 2008). Oleh karena 
itu, perusahaan yang sehat memiliki motivasi untuk mengurangi kewajiban untuk membayar pajak agar mendapatkan keuntungan yang diinginkan. Dengan demikian, non-financial distress dapat diprediksi berpengaruh positif terhadap tax avoidance. Penggunaan variabel non-financial distress adalah kebaruan pada penelitian ini karena belum pernah digunakan oleh literatur terdahulu. Hal ini didasarkan pada hasil penelitian sebelumnya dimana perusahaan yang mengalami financial distress tidak melakukan tax avoidance (Nugroho \& Firmansyah, 2017), sehingga tujuan penelitian ini adalah untuk mengetahui apakah perusahaan yang sehat akan melakukan tax avoidance atau tidak.

$\mathrm{H}_{1}=$ Perusahaan yang tidak mengalami financial distress berpengaruh positif terhadap tax avoidance pada perusahaan subsektor farmasi yang terdaftar di Bursa Efek Indonesia periode 20132018.

Kondisi kedua yang memiliki peran dalam tindakan tax avoidance yaitu perusahaan memiliki koneksi politik. Koneksi politik adalah adanya hubungan antara perusahaan dan pemerintah sehingga perusahaan akan mendapatkan fasilitas yang istimewa. Ferdiawan dan Firmansyah (2017) menemukan bahwa koneksi politik berpengaruh positif terhadap praktik tax avoidance. Dengan kata lain, perusahaan memanfaatkan koneksi di pemerintahan untuk dapat meminimalkan pembayaran pajak. Perusahaan yang mempunyai koneksi mengabaikan konsekuensi negatif yang akan didapatkan ketika mempraktikan tax avoidance (Kim \& Zhang, 2016). Akan tetapi, Dharma \& Ardiana (2016) menemukan bahwa praktik tax avoidance tidak berhubungan dengan koneksi politik yang dimiliki oleh perusahaan. Penelitian ini menggunakan variabel koneksi politik karena perusahaan sangat mungkin berelasi dengan politisi atau pejabat pemerintah sehingga mempunyai kesempatan untuk menggunakan hubungan tersebut untuk mengurangi beban pajak terutang. Penelitian ini berbeda dengan penelitian sebelumnya yang menggunakan perusahaan manufaktur (Ferdiawan \& Firmansyah 2017; Dharma \& Ardiana 2016). Dari pembahaan tersebut, hipotesis yang dirumuskan dalam penelitian ini adalah koneksi politik berpengaruh positif terhadap tax avoidance.

$\mathrm{H}_{2}=$ Koneksi politik berpengaruh positif terhadap tax avoidance pada perusahaan subsektor farmasi yang terdaftar di Bursa Efek Indonesia periode 20132018.

Kondisi lain yang bisa berpengaruh terhadap praktik tax avoidance adalah intensitas persediaan yaitu aktivitas investasi yang dilakukan oleh perusahaan dalam bentuk persediaan (Ardyansah \& Zulaikha, 2014). Adisamartha \& Noviari (2015) menemukan bahwa intensitas persediaan memiliki pengaruh positif dalam praktik tax avoidance pada perusahaan manufaktur periode tahun 2011-2014. Semakin tinggi perputaran persediaan, maka semakin agresif perusahaan untuk mempraktikan tax avoidancekarena akan muncul biaya yang berhubungan dengan persediaan, sehingga laba perusahaan yang dihasilkan akan berkurang atau semakin rendah. Hal ini dapat dijadikan sebagai alat pendukung oleh manajemen untuk melakukan praktik tax avoidance dengan meminimalkan laba yang diperoleh yang akan mempengaruhi kewajiban membayar pajak. Akan tetapi, hasil yang berbeda diungkapkan oleh Andhari \& Sukartha (2017) yang menyebutkan bahwa intensitas persediaan tidak mempengaruhi praktik tax avoidance pada perusahaan sektor pertambangan periode 2013-2015. Oleh sebab itu, dapat disimpulkan bawa intensitas persediaan berpengaruh positif terhadap tax avoidance. Penelitian ini juga mengaplikasikan variabel kontrol yaitu variabel profitabilitas karena peningkatan keuntungan perusahaan bisa berdampak pada besaran pajak terutang (Andikaningprang, Pratomo, \& Kurnia, 2017).

$\mathrm{H}_{4}=$ Intensitas persediaan secara parsial berpengaruh positif terhadap tax avoidance pada perusahaan subsektor farmasi yang terdaftar di Bursa Efek Indonesia periode 20132018.

Penelitian ini bertujuan untuk menganalisis pengaruh non-financial distress, koneksi politik, dan intensitas persediaan dengan profitabilitas sebagai variabel kontrol pada perusahaan subsektor farmasi yang terdaftar di Bursa Efek Indonesia periode 20132018. Subsektor farmasi merupakan salah satu industri prioritas dalam penggerak utama perekonomian sehingga digunakan dalam penelitian ini. Manfaat penelitian ini antara lain: (1) Penelitian ini diharapkan dapat memberikan informasi kepada perusahaan mengenai pengaruh non-financial distress, koneksi politik dan intensitas persediaan terhadap penghindaran pajak. Hal ini memberikan panduan agar pihak manajemen melakukan tax avoidance yang benar tanpa melanggar undang-undang ketentuan pajak yang berlaku. (2) Penelitian ini diharapkan dapat memberikan informasi kepada investor untuk memahami praktik tax avoidance yang dilakukan oleh perusahaan. (3) Penelitian ini diharapkan dapat menjadi bahan evaluasi bagi Direktorat Jenderal Pajak dan masukan dalam pembuatan peraturan agar meminimalisir praktik penghindaran pajak yang dilakukan oleh perusahaan.

\section{METODE}

Penelitian kuantitatif ini menggunakan sumber data laporan keuangan yang diperoleh dari website resmi perusahaan dan Bursa Efek Indonesia. Variabel yang diteliti terdiri dari tax avoidance 
Tabel 1. Kriteria dan Sampel Peneltian

\begin{tabular}{clc}
\hline No & \multicolumn{1}{c}{ Keterangan } & Jumlah \\
\hline 1 & $\begin{array}{l}\text { Perusahaan subsektor farmasi yang terdaftar di Bursa Efek Indonesia periode } \\
\text { 2013-2018 }\end{array}$ & 8 \\
2 & $\begin{array}{l}\text { Perusahaan subsektor farmasi yang tidak konsisten menyampaikan laporan } \\
\text { keuangan tahunan lengkap }\end{array}$ & $(0)$ \\
3 & Perusahaan subsektor farmasi berlaba negatif & $(2)$ \\
4 & Perusahaan subsektor farmasi yang bangkrut dan abu-abu sesuai nilai cut-off & $(1)$ \\
\hline & \multicolumn{2}{c}{ Jumlah sampel penelitian } \\
\hline
\end{tabular}

sebagai variabel terikat dan non-financial distress, koneksi politik, serta intensitas persediaan sebagai variabel bebas, dengan profitabilitas sebagai variabel kontrol. Objek penelitian adalah perusahaan subsektor farmasi di BEI periode 2013-2018 yang mempunyai populasi sebanyak 8 perusahaan dengan kriteria pada Tabel 1. Jumlah sampel adalah lima perusahaan selama 6 tahun sehingga didapatkan 30 data.

\section{Tax Avoidance}

Tax avoidance merupakan praktik untuk mengurangi pajak terutang tetapi tidak bertentangan dengan ketentuan perpajakan (Pohan, 2016). Menurut Hanlon \& Heitzman (2010), terdapat beberapa pengukuran untuk menghitung tax avoidance yaitu GAAP ETR, Current ETR, Cash ETR, Long-run cash ETR, ETR Differential, DTAX, Total BTD, Temporary BTD, Abnormal total BTD, Unrecognized tax benefit, Tax shelter activity, dan Marginal tax rate. Penelitian ini menggunakan CETR karena CETR menggunakan laba pajak sehingga tidak terpengaruh dengan adanya perubahan estimasi seperti penyisihan penilaian atau perindungan pajak (Dyreng, Hanlon, \& Maydew, 2010). CETR ini juga melengkapi kekurangan dari proksi GAAP ETR dalam menghitung tax avoidance. Jika nilai CETR lebih besar dari tarif pajak 25\% maka perusahaan cenderung tidak melakukan tax avoidance dan sebaliknya. Rumus CETR sebagai berikut:

$$
\text { CETR }=\frac{\text { Kas yang dibayar untuk pajak }}{\text { Laba sebelum pajak }}
$$

\section{Non-Financial Distress}

Penelitian ini menggunakan perhitungan model Altman Z-score oleh Altman (1986) karena model tersebut mempunyai tingkat keakuratan sebesar 95\%. Selain itu, terdapat nilai cut-off yang memudahkan pengelompokan perusahaan yang termasuk sehat atau distress. Rumus Altman Z-score adalah sebagai berikut (Altman, 1986):

Nilai cut-off nya adalah jika nilai $Z$ lebih besar dari 1,81 maka perusahaan dikategorikan sebagai perusahaan bangkrut. Jika nilai $\mathrm{Z}$ antara 1,81 dan kurang dari 2,99 maka perusahaan tergolong perusahaan abu-abu. Perusahaan digolongkan ke perusahaan tidak bangkrut jika nilai $\mathrm{Z}$ lebih besar dari 2,99. Dari nilai cut-off tersebut, kategori perusahaan abu-abu dan tidak bangkrut digunakan untuk perusahaan yang sehat.

\section{Koneksi Politik}

Menurut Sudibyo \& Jianfu (2016), koneksi politik diukur dengan variabel dummy dengan menggunakan kriteria yaitu: (a) Salah satu direktur atau komisaris yang juga merupakan anggota pemerintahan, anggota partai politik, dan militer. (b) Salah satu direktur atau komisaris yang juga merupakan mantan anggota pemerintahan, anggota partai politik, dan militer. (c) Salah satu pemilik atau pemegang saham di atas 10\% merupakan anggota pemerintahan, anggota partai politik, dan militer.

\section{Intensitas Persediaan}

Semakin tinggi perputaran persediaan, maka semakin efektif pengelolaan persediaan sehingga biaya persediaan (seperti biaya produksi, operasional, administrasi, dan pemasaran) akan terkendali. Oleh karena itu, entitas yang mempunyai intensitas persediaan tinggi akan agresif terhadap pajak, sehingga intensitas persediaan bisa berpengaruh terhadap tax avoidance. Intensitas persediaan 
diukur dengan membandingkan harga pokok penjualan dengan jumlah persediaan akhir perusahaan (Andhari \& Sukartha, 2017).

\section{Profitabilitas}

Indikator yang digunakan untuk mengukur profitabilitas adalah Return on Assets (ROA), karena ROA dapat menggambarkan sejauh mana suatu perusahaan dapat menghasilkan laba dari aset yang digunakan. Semakin tinggi ROA maka akan semakin bagus kemampuan perusahaan tersebut. Tingginya ROA menunjukkan efesiensi perusahaan dalam mengelola aset.

\section{Teknik Analisis Data}

Analisis regresi adalah metode untuk mengetahui pengaruh antara variabel dependen dengan independen (Basuki \& Prawoto, 2016). Sebelum melakukan regresi, uji asumsi klasik dilakukan terlebih dahulu yang meliputi uji normalitas, uji autokorelasi, uji multikolinieritas dan uji heterokedastisitas. Namun, uji normalitas dan uji autokorelasi tidak perlu dilakukan dalam data panel (Basuki dan Prawoto, 2016) sehingga uji yang dilakukan adalah hanya multikolineritas dan heterokedastisitas. Uji multikolinieritas dilakukan untuk mengetahui hubungan linier antar variabel independen. Besaran korelasi antar variabel harus kurang dari 0,90 agar penelitian bebas dari multikolonieritas. Uji heteroskedastisitas dilakukan untuk mengetahui ketidaksamaan varian untuk variabel bebas yang berbeda. Jika probability lebih dari 0,05, maka data dikatakan bebas dari gejala heteroskedastisitas.

Terdapat tiga tahap dalam menguji kelayakan regresi yaitu uji Chow, uji Hausman dan uji Langrange Multiplier untuk memilih salah satu model yang akan digunakan antara fixed effect, random effect, atau common effect.

Metode analisis yang digunakan merupakan data panel persamaannya dituliskan dibawah ini:

$\mathrm{Yit}=\propto+1 \mathrm{X} 1 \mathrm{it}+2 \mathrm{X} 2 \mathrm{it}+3 \mathrm{X} 3 \mathrm{it}+\varepsilon$

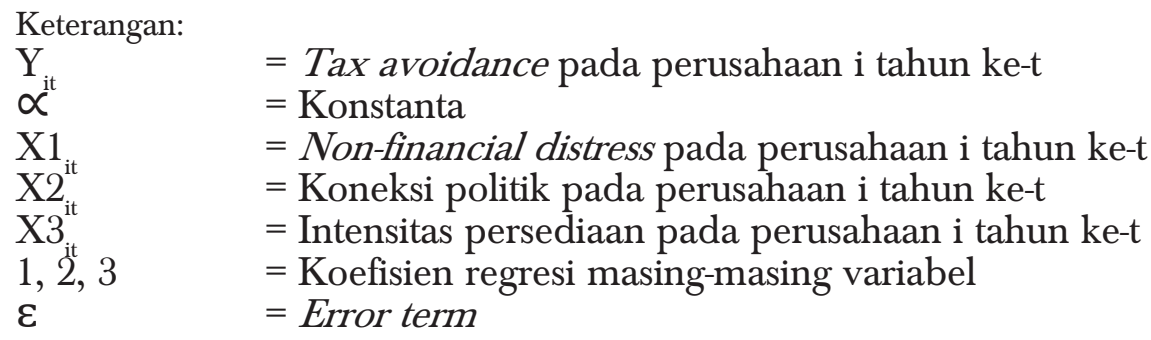

\section{HASIL DAN PEMBAHASAN}

Tabel 2 menunjukkan hasil nilai mean tax avoidance yang lebih kecil daripada nilai simpangan baku sehingga CETR perusahaan subsektor farmasi bervariasi atau heterogen (tidak berkelompok). Nilai maksimum tax avoidance didapatkan oleh KAEF pada tahun 2014 serta TSPC tahun 2017. Nilai minimum tax avoidance didapatkan oleh TSPC pada tahun 2016 dan 2017.

Variabel non-financial distress memiliki nilai mean yang lebih besar dari nilai simpangan baku sehingga data tersebut tidak bervariasi atau berkelompok, yang berarti data dari variabel ini tidak menyebar. Berdasarkan hasil deskriptif, non-financial distress mempunyai mean yang positif yang berarti bahwa kebanyakan perusahaan subsektor farmasi berada pada kategori tidak bangkrut. Nilai maksimum non-financial distress adalah sejumlah 6,60 yang dimiliki oleh KLBF pada tahun 2018, sedangkan nilai minimum sebesar 1,92 didapatkan oleh KAEF pada tahun 2018.

Variabel intensitas persediaan memiliki mean yang lebih besar dibanding nilai simpangan baku sehingga data tersebut tidak bervariasi atau berkelompok. Nilai rerata persediaan mengindikasikan bahwa perputaran persediaan perusahaan subsektor farmasi adalah sebanyak 3,2 kali. Nilai maksimum sebesar 4,77 dimiliki oleh KAEF pada tahun 2013, sedangkan nilai minimumnya sebesar 1,73 didapatkan oleh PYFA pada tahun yang sama.

Profitabilitas juga memiliki data yang tidak bervariasi dengan nilai mean sebesar 0,088 yang lebih besar dari simpangan baku $(0,04)$. Nilai rerata 0,09 menunjukkan bahwa perusahaan mampu memanfaatkan aset untuk menghasilkan laba sebesar $80 \%$. Nilai maksimum profitabilitas dimiliki oleh KLBF tahun 2013, sedangkan nilai minimum didapatkan oleh PYFA pada tahun 2014.

Koneksi politik diukur dengan variabel dummy. Jumlah sampel yang mempunyai koneksi sebanyak 24 sampel (80\%), sedangkan yang tidak memiliki koneksi politik adalah 6 perusahaan (20\%). 
Tabel 2. Uji Statistik Deskriptif Berskala Rasio

\begin{tabular}{lcccc}
\hline \multicolumn{1}{c}{ Keterangan } & Tax Avoidance & $\begin{array}{c}\text { Non-Financial Dis- } \\
\text { tress }\end{array}$ & $\begin{array}{c}\text { Intensitas } \\
\text { Persediaan }\end{array}$ & Profitabilitas \\
\hline Rata-rata & -0.340667 & 4,207609 & 3,215208 & 0,087513 \\
Maksimum & -0.150000 & 6,602020 & 4,768100 & 0,174080 \\
Minimum & -0.720000 & 1,922050 & 1,732120 & 0,015420 \\
Std. Dev. & 0.172225 & 1,189964 & 0,860840 & 0,044083 \\
N & 30 & 30 & 30 & 30 \\
\hline
\end{tabular}

Tabel 3. Uji Multikolonieritas

\begin{tabular}{cccccc}
\hline & $\begin{array}{c}\text { Tax } \\
\text { Avoidance }\end{array}$ & $\begin{array}{c}\text { Non-Finan- } \\
\text { cial Distress }\end{array}$ & $\begin{array}{c}\text { Koneksi } \\
\text { Politik }\end{array}$ & $\begin{array}{c}\text { Intensitas } \\
\text { Persediaan }\end{array}$ & Profitabilitas \\
\hline Tax Avoidance & 1.000000 & -0.051974 & -0.120150 & -0.351884 & 0.114050 \\
Non-Financial Distress & -0.051974 & 1.000000 & 0.432278 & 0.098317 & 0.870834 \\
Koneksi Politik & -0.120150 & 0.432278 & 1.000000 & 0.594796 & 0.642803 \\
Intensitas Persediaan & -0.351884 & 0.098317 & 0.594796 & 1.000000 & 0.178960 \\
Profitabilitas & 0.114050 & 0.870834 & 0.642803 & 0.178960 & 1.000000 \\
\hline
\end{tabular}

Tabel 4. Uji Heterokedastisitas

\begin{tabular}{ccccc}
\hline Variables & Coefficients & Std. Errors & t-Statistics & Probability \\
\hline C & 0.007678 & 0.033010 & 0.232587 & 0.8180 \\
Non-Financial Distress & 0.001165 & 0.010423 & 0.111782 & 0.9119 \\
Koneksi Politik & 0.000245 & 0.000245 & 0.009733 & 0.9923 \\
Intensitas Persediaan & 0.008055 & 0.008055 & 0.917158 & 0.3678 \\
Profitabilitas & 0.018582 & 0.018582 & 0.054275 & 0.9571 \\
\hline
\end{tabular}

Tabel 5. Uji Chow

\begin{tabular}{cccc}
\hline Test Summary & Chi-Square. Statistics & Chi-Square. d.f. & Probability \\
\hline Cross sections random & 149.338315 & 4 & 0.0000 \\
\hline
\end{tabular}

\section{Uji Asumsi Klasik}

Penelitian ini menunjukkan adanya multikolonieritas (Tabel 3) karena nilai korelasi di bawah 0,90. Selain itu, Tabel 4 menunjukkan probabilitas antarvariabel di atas lebih dari 0,05 , sehingga penelitian ini terbebas dari heterokedastisitas (Basuki dan Prawoto, 2016).

\section{Regresi Data Panel}

\section{Uji Chow}

Tabel 5 menunjukkan probabilitas chi-square yaitu 0,0000. Hal ini berarti pengambilan keputusan $\mathrm{H}_{1}$ tidak ditolak atau penelitian ini menggunakan fixed effect model (Basuki dan Prawoto, 2016).

\section{Uji Hausman}

Tabel 6 menunjukkan probabilitas senilai 0,0000 sehingga model yang tepat adalah fixed effect model karena di bawah nilai signifikan sebesar 0,05 . Jika fixed effect modelyang terpilih maka tidak perlu untuk melanjutkan ke uji selanjutnya.

\section{Pengujian Hipotesis}

Tabel menunjukkan probabilitas $F$-statistic senilai 0,000000 artinya secara simultan non-financial distress, koneksi politik, dan intensitas persediaan berpengaruh terhadap tax avoidance. 
Tabel 6. Uji Hausman

\begin{tabular}{cccc}
\hline Effect-Test & Statistics & d.f & Probability \\
\hline Cross sections F & 37.334579 & $(4.21)$ & 0.0000 \\
Cross sections Chi square & 62.797923 & 4 & 0.0000 \\
\hline
\end{tabular}

Tabel 7. Uji Parsial

\begin{tabular}{lcccc}
\hline \multicolumn{1}{c}{ Variables } & Coefficients & Std. Error & t - Statistics & Probability \\
\hline C & 147.6909 & 57.14842 & 2.584339 & 0.0173 \\
Non-Financial Distress & -0.072014 & 0.031722 & -2.270157 & 0.0338 \\
Koneksi Politik & -185.1178 & 71.41229 & -2.592240 & 0.0170 \\
Intensitas Persediaan & 0.061371 & 0.034264 & 1.791130 & 0.0877 \\
Profitabilitas & 1.994562 & 0.802688 & 2.484854 & 0.0215 \\
\hline
\end{tabular}

Adjusted $r^{2}$ senilai 0,881463 yang mengindikasi bahwa variabel bebas (non-financial distress, koneksi politik, intensitas persediaan, dan profitabilitas) mampu menjelaskan tax avoidance sebagai variabel terikat sebesar $88,14 \%$ dan sisanya $11,86 \%$ dijelaskan oleh variabel yang lain.

Berdasarkan hasil uji parsial, non-financial distress memiliki nilai 0,0338 yang menunjukan bahwa $\mathrm{H}_{01}$ ditolak dan $\mathrm{H}_{21}$ tidak ditolak. Hal tersebut berarti perusahaan yang mengalami non-financial distress berpengaruh pada tax avoidance tetapi terdapat perbedaan pada hasil koefisien yang menunjukkan arah negatif. Koefisien regresi non-financial distress sejumlah -0,072014 memperlihatkan ke arah negatif. Hal ini berarti apabila CETR meningkat sebesar satu satuan dan nilai variabel tetap maka CETR akan berkurang sebesar 0,072014 satuan yang menandakan bahwa semakin tinggi koefisien non-financial distress maka perusahaan tidak termotivasi untuk melakukan praktik tax avoidance.

Koneksi politik mempunyai nilai 0,0174 yang dapat diartikan bahwa $\mathrm{H}_{02}$ ditolak dan $\mathrm{H}_{\mathrm{a} 2}$ tidak ditolak. Oleh karena itu, koneksi politik mempunyai pengaruh pada tax avoidance tetapi terdapat perbedaan hasil pada koefisien yang menunjukkan arah negatif. Koefisien regresi koneksi politik sejumlah -185,1178 memperlihatkan ke arah negatif yang berarti apabila CETR meningkat sebesar satu satuan dan variable, tetap maka CETR akan berkurang sejumlah 185,1178 satuan. Hal tersebut berarti semakin banyak perusahaan yang mempunyai hubungan politik tidak akan melakukan tax avoidance.

Intensitas persediaan memiliki nilai 0,0874 yang dapat diartikan bahwa $\mathrm{H}_{03}$ tidak ditolak dan $\mathrm{H}_{a 3}$ ditolak maka intensitas persediaan tidak mempengaruhi tax avoidance. Koefisien regresi intensitas persediaan $\left(\mathrm{X}_{3}\right)$ sejumlah 0,061371 memperlihatkan ke arah positif yang berarti apabila CETR meningkat sebesar satu satuan dan variabel tetap, maka CETR akan bertambah sejumlah 0,061371 satuan.

\section{Pembahasan}

Hasil penelitian menunjukkan bahwa non-financial distress berpengaruh negatif terhadap tax avoidance. Hasil ini menunjukkan ketidaksesuaian dengan hipotesis yang ditetapkan yaitu perusahaan yang tidak mengalami kesulitan keuangan melakukan praktik tax avoidance. Perusahaan yang sehat telah memiliki keuntungan sehingga berbeda perusahaan yang mengalami kesulitan keuangan. Perusahaan yang mengalami kesulitan keuangan akan melakukan tax avoidance karena adanya perbedaan kepentingan antara pihak manajemen yang tertekan untuk meminimalkan pengeluaran agar perusahaan dapat terus beroperasi dengan pemerintah yang menginginkan penerimaan pajak yang besar.

Hasil penelitian ini juga menunjukkan ketidaksesuaian dengan hipotesis yang ditetapkan yaitu koneksi politik berpengaruh positif terhadap tax avoidance. Perusahaan yang memiliki hubungan dengan politisi atau pemerintah dalam penelitian ini adalah sebanyak 24 dari 30 sampel, sehingga perusahaan yang mempunyai hubungan dengan pemerintah atau politisi tidak memanfaatkan hubungan istimewa tersebut. Penelitian ini menemukan arah negatif untuk koneksi politik sehingga bertentangan dengan hipotesis yang ditetapkan yaitu koneksi politik berpengaruh positif terhadap tax avoidance. Arah negatif ini sesuai dengan temuan Mulyani, Darminto, \& Pamungkas (2014). Walaupun terjadi perbedaan kepentingan, perusahaan tetap tidak ingin menerima risiko yang membuat citra perusahaan menjadi buruk sehingga tidak melakukan tax avoidance.

Ketidaksesuaian hasil dengan hipotesis juga terjadi di hipotesis ketiga yang ditetapkan yaitu intensitas persediaan berpengaruh positif terhadap tax avoidance. Data penelitian menunjukkan 
bahwa rata-rata intensitas persediaan cukup rendah. Namun, temuan ini sama dengan temuan Andhari \& Sukartha (2017). Jika dikaitkan dengan teori agensi, maka hal ini akan mengurangi biaya agensi karena pihak agent telah melakukan tindakan yang sesuai dengan keinginan principal. Terkait dengan profitabilitas, ROA juga tidak berpengaruh terhadap tax avoidance. Data penelitian menunjukkan bahwa ROA minimum tidak bernilai negatif sehingga kondisi keuangan semua perusahaan sangat baik atau tidak mengalami kerugian. Dengan demikian, perusahaan tidak mempraktikan tax avoidance.

\section{SIMPULAN}

Hasil penelitian ini menunjukkan bahwa perusahaan yang sehat cenderung tidak melakukan praktik tax avoidance. Adanya hubungan negatif antara kedua variabel ini mengindikasikan bahwa perusahaan berusaha menjaga citra baik perusahaan dengan melaksanakan kewajiban perpajakannya sesuai dengan ketentuan perpajakan yang berlaku di Indonesia, meskipun pembayaran pajak cukup tinggi. Selain itu, koneksi politik juga tidak digunakan untuk mencari keuntungan dengan melakukan tax avoidance karena untuk menjaga citra perusahaan. Penelitian ini memiliki keterbatasan dari kekurangan sumber penelitian terdahulu untuk variabel non-financial distress dikarenakan variabel ini merupakan kebaharuan. Penelitian selanjutnya dapat memperbaiki penelitian ini dengan menggunakan sampel perusahaan selain perusahaan subsektor farmasi yang terdaftar di Bursa Efek Indonesia misalnya perusahaan yang terdaftar di Indeks Kompas100, Indeks LQ45, Jakarta Islamic Index (JII) untuk mengetahui praktik tax avoidance yang terjadi di industri lain.

\section{DAFTAR RUJUKAN}

Adisamartha, I. B., \& Noviari, N. (2015). Pengaruh Likuiditas, Leverage, Intensitas Persediaan, dan Intensitas Aset Tetap pada Tingkat Agresivitas Wajib Pajak Badan. E-Jurnal Akuntansi Universitas Udayana, 13(3), 973-1000.

Altman, E. I. (1986). The Prediction of Corporate Bankruptcy: A Discriminant Analysis. The Journal of Finance, 23(1), 193-194. doi:10.1111/j.1540-621.1968.tb03007.x.

Andhari, P. A., \& Sukartha, I. M. (2017). Pengaruh Pengungkapan Corporate Social Responsibility, Profitabilitas, Inventory Intensity, Capital Intensity, dan Leverage pada Agresivitas Pajak. E-Jurnal Akuntansi Universitas Udayana, 18(3), 2115-2142.

Andikaningprang, A., Pratomo, D., \& Kurnia. (2017). Pengaruh Foreign Investors' Interest dengan Variabel Kontrol Profitabilitas, Ukuran Perusahaan, dan Leverage terhadap Tax Avoidance. E-Proceeding of Management, 4(2), 1521-1526.

Ardyansah, D., \& Zulaikha. (2014). Pengaruh Size, Leverage, Profitability, Capital Intensity Ratio, dan Komisaris Independen terhadap Effective Tax Rate (ETR). Diponegoro Journal of Accounting, 3(2), $1-9$.

Basuki, A. T., \& Prawoto, N. (2016). Analisis Regresi dalam Penelitian Ekonomi \& Bisnis. Depok: PT Rajagrafindo Persada.

Dharma, I. M., \& Ardiana, P. A. (2016). Pengaruh Leverage, Intensitas Aset Tetap, Ukuran Perusahaan, dan Koneksi Politik terhadap Tax Avoidance. E-Jurnal Akuntansi Universitas Udayana, 15(1), 584-613.

Dyreng, S. D., Hanlon, M., \& Maydew, E. (2008). Long-Run Corporate Tax Avoidance. The Accounting Review, 83(1), 61-82. doi:10.2308/accr.2008.83.1.61.

Dyreng, S. D., Hanlon, M., \& Maydew, E. (2010). The Effects of Executives on Corporate Tax Avoidance. The Accounting Review, 85(4), 1163-1189. doi:10.2308/accr.2010.85.4.1163.

Ferdiawan, Y., \& Firmansyah, A. (2017). Pengaruh Political Connection, Foreign Activity, dan Real Earning Management terhadap Tax Avoidance. Jurnal Riset Akuntansi dan Keuangan, 5(3), 1601-1624. doi:10.17509/jrak.v5i3.9223.

Hanafi, M., \& Halim, A. (2012). Analisis Laporan Keuangan. Yogyakarta: UPP STIM YKPN.

Hanafi, U., \& Harto, P. (2014). Analisis Pengaruh Kompensasi Eksekutif, Kepemilikan Saham Eksekutif, dan Preferensi Risiko Eksekutif terhadap Penghindaran Pajak Perusahaan. Diponegoro Journal of Accounting, 3(2), 1-11. 
Hanlon, M., \& Heitzman, S. (2010). A Review of Tax Research. Journal of Accounting and Economics, 50, 127-178. doi: 10.1016/j.jacceco.2010.09.002.

Jensen, M. C., \& Meckling, W. H. (1976). The Theory of the Firm: Manjerial Behavior, Agency Cost, and Ownership Structure. Journal of Financial and Economic, 3(4), 305-360. doi:10.1016/0304405X(76)90026-X.

Kasmir. (2015). Analisis Laporan Keuangan. Jakarta: Rajawali Pers.

Kim, C., \& Zhang, L. (2016). Corporate Political Connections and Tax Aggressiveness. Contemporary Accounting Reseach, 33(1), 78-114. doi:10.1111/1911-3846.12150.

Mardiasmo. (2019). Perpajakan. Yogyakarta: CV Andi Offset.

Mulyani, S., Darminto, \& Pamungkas, M. G. W. E. N. (2014). Pengaruh Karakteristik Perusahaan, Koneksi Politik, dan Reformasi Perpajakan terhadap Penghindaran Pajak. Jurnal Mahasiswa Perpajakan, 2(1), 1-9.

Nugroho, S. A., \& Firmansyah, A. (2017). Pengaruh Financial Distress, Real Earnings Management, dan Corporate Governance terhadap Tax Aggressiveness. Journal of Applied Business Administration, 1(2), 163-182. doi:10.30871/jaba.v1i2.616.

Oktamawati, M. (2017). Pengaruh Karakter Eksekutif, Komite Audit, Ukuran Perusahaan, Leverage, Pertumbuhan Penjualan, dan Profitabilitas terhadap Tax Avoidance. Jurnal Akuntansi Bisnis, 15(1), 23-40. doi:10.24167/jab.v15i1.1349.

Pemerintah Indonesia. (2009). Undang-Undang Republik Indonesia Nomor 16 Tahun 2009 tentang Penetapan Peraturan Pemerintah Pengganti Undang-Undang Nomor 5 Tahun 2008 tentang Perubahan Keempat atas Undang-Undang Nomor 6 Tahun 1983 tentang Ketentuan Umum dan Tata Cara Perpajakan Menjadi Undang-Undang. Lembaran Negara Republik Indonesia Tahun 2009 Nomor 62. Jakarta: Sekretariat Negara.

Pohan, C. A. (2016). Manajemen Perpajakan. Jakarta: PT. Gramedia Pustaka Umum.

Purwoto, L. (2011). Pengaruh Koneksi Politis, Kepemilikan Pemerintah, dan Keburaman Laporan Keuangan terhadap Kesinkronan dan Risiko Crash Harga Saham. (Disertasi, Universitas Gadjah Mada, Yogyakarta).

Santoso, I., \& Rahayu, N. (2013). Corporate Tax Management. Jakarta: Observation \& Research of Taxation (Ortax).

Sari, D. (2013). Konsep Dasar Perpajakan. Bandung: PT Refika Aditama.

Sudibyo, Y. A., \& Jianfu, S. (2016). Political Connections, State Owned Enterprises, and Tax Avoidance: An Evidance from Indonesia. Corporate Ownership \& Control, 13(3), 279-283. doi:10.22495/cocv13i3c2p2.

Watts, R. L., \& Zimmerman, J. L. (1986). Positive Accounting Theory. New Jersey: Prentice-Hall. 